\title{
Desbordes performáticos: del estallido de los museos a las zonas de dolor
}

\section{Performatic overflows: from the explosion of the museums to the zones of pain}

\section{Transbordamentos performáticos: da explosão dos museus às zonas de dor}

\author{
Yasmina Azziz ${ }^{1}$ y Kildina Veljacic ${ }^{2}$
}

\begin{abstract}
Resumen
En este artículo buscamos comentar la trayectoria de lo performático a la performance en dos autoras latinoamericanas: Cristina Peri Rossi y Diamela Eltit, entendiendo a su literatura como una forma de revuelta frente a la situación política y social del Cono Sur en el período que abarca los años de publicación de estos textos (1969-1983). Analizaremos, por otra parte, acontecimientos que se presentan en sus ficciones narrativas, desbordarse en la presencialidad corporal de la artista en la plaza pública como acción política. Nos interesa indagar en el tema del género, en la crítica a la sociedad del espectáculo, y en las formas de contracultura y resistencia a los regímenes autoritarios.
\end{abstract}

Palabras clave: Cristina Peri Rossi; Diamela Eltit; narrativa latinoamericana; performance; revuelta.

\begin{abstract}
In this article we attempt to comment the trajectory of performatic actions to performance in two latinamerican authors: Cristina Peri Rossi and Diamela Eltit, understanding their literature as a form of revolt against the social and political situation of the Cono Sur that encompasses the years of publication of these texts (1969-1983). We will also analyze events that present themselves in their narrative fictions and the overflow on the corporal elements of the artist in the public park as a political action. We are interested in investigating gender, the critique to the society of spectacle, and in the forms of counterculture and resistance to authoritarian regimes.
\end{abstract}

Keywords: Cristina Peri Rossi; Diamela Eltit; latinamerican narrative; performance; revolt.

\section{Resumo}

\footnotetext{
${ }^{1}$ Yasmina Azziz; estudiante de la Licenciatura de Letras en la Facultad de Humanidades y Ciencias de la Educación de la Universidad de la República; Integra el equipo de investigación "Ellas dicen", dirigido por la Dra. Claudia Pérez. Departamento de Teoría Literaria y Letras de FHCE-UDELAR; Solymar; Canelones; Uruguay; azzizyb@gmail.com

${ }^{2}$ Kildina Veljacic; Doctoranda en Filosofía y Letras y Magíster en Ciencias Humanas, opción Literatura Latinoamericana, por la Facultad de Humanidades y Ciencias de la Educación de la Universidad de la República; Profesora de Literatura egresada del Instituto Profesores Artigas. Docente en el Consejo de Enseñanza Secundaria; Integra el equipo de investigación "Ellas dicen", dirigido por la Dra. Claudia Pérez. Departamento de Teoría Literaria y Letras de FHCE-UDELAR. Solymar, Canelones, Uruguay; anakildina@gmail.com
} 
Neste artigo, pretende-se abordar a trajetória do performático e da performance em duas autoras latinoamericanas: Cristina Peri Rossi e Diamela Eltit, compreendendo suas literaturas como formas de revolta diante o cenário sócio-político do Cone Sul no período que abrange os anos de publicações desses textos (1969-1983). Também serão analisados eventos que se fazem presentes em suas ficções narrativas, transbordando-se na apresentação da artista em praça pública como um ato político. Estamos interessados em investigar a questão do gênero, a crítica à sociedade do espetáculo e as formas de contracultura e resistência aos regimes autoritários.

Palavras-chave: Cristina Peri Rossi; Diamela Eltit, Narrativa latino-americana; Performance; Revolta.

\section{Introducción}

Presentaremos nuestros avances de la investigación de mujeres escritoras de la generación de los 60 en el Cono Sur buscando comparar sus trayectorias para encontrar continuidades y discontinuidades, semejanzas y peculiaridades en las producciones de mujeres en lo que refiere a la construcción del género, al poder performativo y performático de la palabra y del cuerpo como acción política de resistencia.

La revuelta del 68 y los enfrentamientos callejeros se extendieron por Europa, Estados Unidos y América Latina canalizando el descontento creciente de los jóvenes que luchaban por transformar las bases de las políticas capitalistas, en el contexto de la guerra fría. Muchos de los cuestionamientos de la movida contracultural tuvieron una influencia profunda en los cambios que se produjeron en la relación del arte con la política, el cuerpo y la construcción de la subjetividad que se desarrollaron en las décadas siguientes. Partiendo de las problemáticas nociones de performatividad y performance, observaremos estos desbordes multimediales en dos escritoras latinoamericanas:la uruguaya, Cristina Peri Rossi (1941), y la chilena, Diamela Eltit (1947), en el crítico contexto de los regímenes represivos del Cono Sur. Haremos un recorrido que irá desde Los museos abandonados (1968), de Cristina Peri Rossi, a la novela Lumpérica (1983), de Diamela Eltit y su performance Zonas de dolor (1980). Analizaremos acontecimientos que se presentan en sus ficciones narrativas primero, para extenderse a la presentación corporal de la artista en la plaza pública

como acción política.

Pensaremos en los modos de "hacer cultura" como formas de una performance plural, siguiendo el planteo realizado por Taylor (2001) para poder valorar el poder instituyente de sus revueltas:

Las conductas de sujeción civil, resistencia, ciudadanía, género, etnicidad, e identidad sexual, por ejemplo, son ensayadas y reproducidas a diario en la esfera pública. Entender este fenómeno como performance sugiere que la performance también funciona como una epistemología. Como práctica in-corporada, de manera conjunta con otros discursos culturales, la performance ofrece una determinada forma de conocimiento. (...) la comprensión de performance como un fenómeno simultáneamente "real" y "construido" (TAYLOR, 2001). 
Observaremos un momento particular de la historia en donde se producen profundas transformaciones en la relación de las escritoras con las políticas culturales dominantes y las consecuencias de este conflicto en sus procesos creativos. Prestaremos especial atención a los procesos de subjetivación disidentes, a la literatura entendida como revuelta, término tomado de Kristeva, quien formula la "aventura literaria" en el sentido de retorno al pasado y proceso psíquico. "Se produce allí una modificación, no repetición sino una reformulación de nuestro mapa psíquico" (KRISTEVA, 1998, p.94). La lectura de los textos literarios también requiere de cierta apertura o "aptitud para la revuelta" subjetiva, particularmente en los contextos de crisis social e institucional. Las obras:

Se nos aparecen entonces -y solo entonces- no como fetiches u objetos muertos correspondientes a estados definidos de la historia o la retórica, sino como otra de las tantas experiencias de supervivencia psíquica para quienes se jugaron en ellos, y para nosotros mismos" (KRISTEVA, 1998, p. 96).

La performance, entendida no solamente en la dinámica de la interacción social sino como disciplina artística, surge en un momento en donde el arte y la literatura se intersectan con la política y en el cuerpo. La obra artística deja de concebirse como objeto para pasar a la obra como acción. La contracultura de los años 60 cuestionará las instituciones, la mercantilización y fetichización de la obra de arte en la cultura de masas, la censura y la violencia del terrorismo de estado de los regímenes autoritarios. Buscará, como alternativa ética y estética, el compromiso corporal y político del artista y del público participante en la construcción del acontecimiento artístico anticipando la performance como forma de "resistencia" que aparecerá en los contextos dictatoriales de los años 80 en el Cono Sur (GARBATZKY, 2013, p. 25).

Erika Fischer-Lichte (2011) señala el giro performático que, desde la década de los sesenta, comienza a observarse en el arte, producido ahora como acontecimiento. En los años 70 y 80 Florencia Garramuño (2009, p. 34-35) registra las experiencias artísticas que se desarrollan en Argentina y Brasil desde la "tactilidad de la experiencia" como apertura de la obra hacia nuevos “experimentos vitales” e Irina Garbatzski (2013) se detiene en el fenómeno de la performance poética en Argentina y Uruguay en los años 80 que "postula una búsqueda de tradiciones alternativas con las cuales resolver conflictos políticos e identitarios" (2013, p. 13).

Siguiendo esta dirección, presentaremos dos momentos de la contracultura literaria en Uruguay y en Chile. El primero en el emblemático año 68, en el período pre-dictatorial uruguayo, que contiene un germen ficcional y alegórico de la revuelta. Después observaremos 
el desborde del soporte textual en la performance multimedia que presenta el cuerpo como resistencia en la escena dictatorial de los años 80 en Chile.

\section{Los refugios de Cristina Peri Rossi}

A mediados del siglo XX, Uruguay registra el aumento de la población urbana, el incremento del poder adquisitivo y la demanda de productos de consumo cultural debido al respaldo de un Estado benefactor. El público lector creció y la industria editorial tomó impulso (DA ROSA, 1996, p. 113-114). Pero en los años sesenta, se produce una crisis económica que afectará profundamente al país, comprometiendo el proyecto cultural de la década anterior, las instituciones y planteando nuevas tensiones. Es el momento de la llamada "generación crítica" (RAMA, 1972, p. 19) que reunió a intelectuales en torno al Semanario Marcha, a las revistas literarias y diarios de la época. También la Feria Nacional de Libros y Grabados (1961) impulsada por Nancy Bacelo intervino en el campo cultural desde sus concursos, mesas redondas y la presentación de libros de autores uruguayos (RAMA, 1972; OREGGIONI, 1991 en MIRZA, 2007, p. 73). La creación de las editoriales Alfa (1960), Banda Oriental (1961) y Arca (1962) buscarán la difusión de la literatura latinoamericana y el compromiso en la construcción de una literatura y cultura nacional. La editorial Arca, dirigida por Ángel Rama y José Pedro Díaz, organizará un concurso buscando la promoción de nuevas voces en el espacio local. Cristina Peri Rossi obtendrá el primer lugar en el "Premio de los jóvenes de 1968" con el libro Los museos abandonados (1969).

Los museos abandonados es el segundo libro de Peri Rossi, reúne cuatro cuentos: "Los extraños objetos voladores" y el tríptico que se inicia en "Los juegos", continúa en "Un cuento para Eurídice" y termina en "Los refugios". Esta agrupación, dice la autora en el Semanario Marcha, se propone como una unidad ya que los tres están "protagonizados por una pareja que vive una situación límite: la destrucción del mundo, de una civilización, de un orden social, de una estructura, de un tipo especial de cultura, de una manera de concebir el amor, el arte, la sociedad.” (1968, p.29). Esta ficción funciona como una alegoría de la descomposición social, de la crisis económica, de valores, de las estructuras míticas sobre las que se asentaba.

La escritora a partir del premio otorgado por la editorial Arca comienza a colaborar en el Semanario Marcha, influyente no solamente en Uruguay sino en Hispanoamérica, hasta que su nombre y sus textos fueron prohibidos. Ángel Rama (1972) ubica a Cristina Peri Rossi en la posible "Generación del 69" o "Generación de la acción”, junto a Mercedes Rein, Teresa Porsekanski y Mario Levrero. En estos escritores uruguayos, la imaginación se vincula a la 
modulación armada del combate político social, proponiendo una modificación sustancial en la política nacional (RAMA, p. 221, en BRAVO, 2015, p. 94). El golpe de estado de 1973 dará inicio a la dictadura que en Uruguay que se extenderá hasta 1985. Peri Rossi deberá exiliarse en Barcelona, poniendo fin a las utopías revolucionarias de liberación y un hombre nuevo.

Hemos elegido el análisis de un cuento de este libro premiado porque resulta representativo de "generación acción" y su apuesta imaginativa, experimental, en donde la subjetividad se involucra en los conflictos políticos de su tiempo. A través de las transformaciones del personaje de Ariadna, en el cuento "Los refugios", analizaremos la construcción de la subjetividad femenina que realiza la publicidad, la cultura de masas y cómo la alteración de lo cotidiano de las revueltas juveniles cambian su autopercepción, provocando un extrañamiento capaz de hacerla consciente de la alienación en la que se encontraba.

Las representaciones del imaginario social logran instituir formas de sentir, pensar y actuar. Peri Rossi nos muestra cómo es posible producir, reproducir y destruir el sistema, cambiando el pasado a través de nuevas narrativas y, con él, el futuro. También observaremos extraordinarios eventos cuyo carácter instituyente revela la estructura del sistema y sus fisuras internas. La cultura es pensada por Peri Rossi como un proceso en el que se crean imaginarios, discursos, significados, valores, prácticas y experiencias. El foco está en la experiencia estética, ética y erótica. Esta experiencia es multisensorial, se trata de una experiencia emotiva y expresiva que compromete al cuerpo. La singularidad del acontecimiento, la revuelta de jóvenes revolucionarios, en donde la corporalidad de la experiencia se pone de relieve en tan alto grado, puede ser analizado como una performance. Observa cómo se produce una subjetividad de las mujeres cuyas percepciones, afectos y comportamientos inconscientes tienden a reproducir el sistema que las aliena. En estas narraciones se realiza una crítica al sistema capitalista que pretende apropiarse de la fuerza de trabajo y del deseo.

Ariadna, personaje femenino de "Los refugios", es actriz, trabajaba en un estudio cinematográfico como doble. Es la encargada de realizar las escenas de riesgo, mientras la actriz principal ocupa los primeros planos. Recuerda esta actividad como un tiempo de cansancio, en donde se suceden las escenas fragmentadas, los gestos y las palabras de los otros, repetidas hasta el agotamiento, entre los distintos planos, las luces y los gestos estereotipados. Dice que, desde que entró en el estudio, no ha tenido tiempo de pensar. Fue elegida por su cuerpo y absorbida por la dinámica fílmica en una vorágine imparable del mercado. 
Para Debord el espectáculo es la última figura del capitalismo y la última forma de alienación del sujeto. La sociedad del espectáculo suplanta la realidad por la imagen, lo vivo por su representación, al punto de ser "la negación visible de la vida, como una negación de la vida que se ha hecho visible (BARRÍA JARA, 2011, p. 112).

Alicia Gallegos, por otro lado, habla de los "mecanismos de semiotización que fabrican subjetividades con percepciones, afectos y comportamientos inconscientes que lo reproducen y vigorizan buscando la sujeción de los individuos" (GALLEGOS, 2003, p.2). Esto es visible en el relato del estudio de Ariadna cuyos recuerdos parecen responder al ritmo y la dinámica fílmica. Su experiencia corporal se fragmenta sin poder reconocerse como propia en el montaje de la imagen final que la presenta:

Después siempre estaba yo, de perfil, de costado, de espaldas, en el tren, en la escollera, en la península. De lejos la cámara atenúa las diferencias. Solamente el rostro no es el mismo. Y no bien se ha terminado una, ya comienza la otra. No se puede detener. Nada se detiene nunca, filmando. Detenerse es perder para siempre, es perderse, es renunciar. Se busca por aquí, por acá y cuando te encuentran, hazlo, no te detengas. Hoy una, mañana otra. Hay que estar en varios lados al mismo tiempo (PERI ROSSI, 1969, p.130).

A través de un diálogo con el modelador relata que hacía diez años que no salía a la calle cuando sintió los gritos y el llamado. En medio del impacto emocional, describe una manifestación de muchachos que la invitan a sumarse a la revuelta mientras agitan carteles en donde se lee: "Basta de guerra. Queremos paz", "Socialismo sí, guerra no". "Desterrar la propiedad privada", "Socialismo es justicia", "Socialismo es progreso", "No nos dejemos matar más".

La alienación a la que se ha visto sometida hace que no le encuentre sentido a las palabras, pero su empatía emocional la lleva a adherir intuitivamente a su causa. Turner (2002) afirma que es en el margen, en el espacio liminal, donde se producen efectos de extrañamiento que generan nuevos sentidos. Dice Ariadna: " $P-a-z$ no sé qué quiere decir esa palabra. So-cia-lis-mo, también es una palabra confusa. No sé bien qué quiere decir" (PERI ROSSI, 1969, p.121).

Los jóvenes, desde un pensamiento crítico, radical, encuentran formas de resistencia al capitalismo. Crean un movimiento social capaz de incidir en la trama socio- histórica y política para transformarla pero se encontrarán con la violencia de las fuerzas represivas. Ariadna es testigo de cómo la manifestación se torna violenta, cómo los jóvenes dan vuelta bancos, cantan y lanzan trozos del pavimento roto cuando comienzan a reprimirlos, a dispararles, entre luces, gritos y sirenas. Le relata al modelador en una enumeración absurda, abyecta, alegórica, cómo los jóvenes caían, "perdían partes de sí mismos: perdían brazos, cabellos, pieles, niños, las cosas que llevaban” (PERI ROSSI, 1969, p.124), mientras otras 
personas se agolpaban en las puertas de los refugios cargando sus pertenencias. Se instala un estado de guerra, una escena apocalíptica, confusa, en la que se ve involucrada. De pronto se prenden luces que la encandilan, estallan los gases que no la dejan ver, ni respirar, unos se desmayan, otros sufren ataques, en medio del amontonamiento y el miedo. Se cierran las puertas de los refugios y muchos quedan afuera, resistiendo

Desde el museo, Ariadna recuerda a los muchachos celebrantes cayendo heridos por los disparos. Evoca sus palabras: "Somos jóvenes y luchamos", la invitación: "Acompáñenos", la fe en el triunfo rápido, en el festejo de la victoria, la risa, los besos prometidos. Solo unos pocos sobreviven. Ella buscó refugio, corrió asustada hacia donde corrían todos. ¿Por qué? Porque "los todos asustan menos que los pocos” (PERI ROSSI, 1969, p. 132). Pero esta experiencia la ha cambiado, ya no quiere dormir más. Escucha los gritos afuera y sabe que están allí, avanzando, vivos, en algún lugar y los espera. La escena de la revuelta puede pensarse como una performance política. Y toda performance abre un espacio de reflexión en el que las personas pueden reconocerse como miembros de una comunidad. Verse es despertar, no estar dormido. Los elementos cotidianos entonces, se reconfiguran en la interacción.

Por otro lado, contrastando con el mundo exterior, en el museo, nada sucede. El tiempo se detiene y los objetos se almacenan como pequeños testamentos para el futuro. Para Derrida, el objeto del Museo esconde una promesa, algo que espera ser descubierto, descifrado, algo desconocido que le ofrece una aureola especial y lo hace seleccionable (DERRIDA, 1997, p. 36). Pero, “¿Cómo sabe qué querrá de nosotros el tiempo futuro?” (PERI ROSSI, 1969, p.134). En una hoja Ariadna escribe de distintas maneras el siglo XXI, ordenando tipográficamente los números en la página como si se tratara de un poema vanguardista.

El modelador habita el museo vacío, las paredes y corredores demolidos para hacer una gran explanada, estatuas clasificadas en cajas. Antes, soñaba con navegar, pero le ofrecieron remodelar el museo y aceptó quedarse mientras partían las naves. Tiene todo el tiempo para hacerlo, por eso vive en un no tiempo en donde nada sucede. Sueña con retener a Ariadna, pero ella está atenta a los gritos de los jóvenes afuera, se preocupa, se asusta, siente y responde a su llamado. Aunque no entiende la palabra "luchar", siente sus risas, sus gritos, su riesgo, algo que el modelador no puede o no siente porque está ocupado, armando la figura paradójica de "Los Estables" que es una instalación enorme de metal en el centro del patio, un mastodonte de alambre y estaño. Ella se resiste a ser un símbolo, una imagen, la poesía, una estatua sobre una base de metal creada por el modelador. No quiere estar dormida, no quiere 
representar otro papel más. El Museo es un refugio insuficiente, la vida corre afuera.

Los modos de representación y la experiencia del espacio tiempo en una cultura pueden cambiar. Para Walter Benjamin, estos cambios se entienden mejor en las metáforas espaciales que en los términos históricos (BENJAMIN, 2005, p. 462, 463). En "El libro de los pasajes" utilizará la teoría del montaje en el arte y en el archivo para desmantelar el estatus privilegiado y el sistema jerárquico perpetrado por la unicidad del signo.

El concepto del Museo como archivo histórico migra subversivamente en el cuento de Peri Rossi hacia la idea de un espacio performático en donde los cuerpos se mueven, juegan con los objetos y los destruyen desmontando su orden, su logos. El Museo es desmontado y destruido según el deseo del modelador. Ariadna, por otro lado, arma un montículo con las cajas en donde se guardan las estatuas para poder ver más allá del muro. Desespera y espera a los "furiosos sobrevivientes". Finalmente estos llegan, han vencido y "como escarabajos" se lanzan sobre "la ciudad hecha una gran explanada mortuoria", "trayendo un poco de su furia vertiginosa, la doméstica, la cotidiana, algo de su euforia territorial, su énfasis" (PERI ROSSI, 1969, p. 137).

Lo performativo de sus manifestaciones no está en la repetición ritual sino en su capacidad de generar un experiencia social nueva, instituyente que, en su apertura, contagie su potencia sensorio motriz y, en su espectacularidad dionisíaca, revolucionaria, permita una adhesión emocional capaz de legitimar los actos, sacrificando la propia identidad en este proceso.

El ruido que producen estos "sobrevividos" se compara con una montaña en movimiento, con un monte puesto a andar, con "un mar que muge y se levanta", "un toro de lid que atropella, cabeza abajo, buscándole el cuerpo" (PERI ROSSI, 1969, p. 138). Peri Rossi utiliza todos los recursos poéticos en este relato dialogado: aliteraciones, imágenes sensoriales y dinámicas comparaciones, inserta poemas, utiliza metáforas para mostrar la fuerza instintiva de los sobrevividos que llegan castigando. La ciudad se presenta con sus "ubres henchidas" y la noche con su "víscera hinchada y oscura" (169, p. 139). Las metáforas sugieren un alumbramiento o la inminente emergencia de lo abyecto.

Julia Kristeva entiende lo abyecto como "aquello que perturba una identidad, un sistema, un orden. Aquello que no respeta límites, los lugares, las reglas. La complicidad, lo ambiguo, lo mixto" (KRISTEVA, 1987, p. 11). El escritor -indica Kristeva- que llega a fascinarse por lo abyecto "se imagina su lógica, se proyecta en ella, la introyecta y por ende pervierte la lengua -el estilo y el contenido-" (KRISTEVA, 1980, p. 23). Sugiere que la literatura es el significante privilegiado de la abyección e intenta mostrar que, lejos de ser un 
margen menor de nuestra cultura, la literatura de lo abyecto "es la codificación última de nuestras crisis, de nuestros apocalipsis más íntimos y más graves” (KRISTEVA, 1980, p. 23). María José Bruña Bragado dice que la literatura de Cristina Peri Rossi es esencialmente abyecta, nacida "del reconocimiento de una pérdida esencial o el desmarcarse conscientemente de las convenciones acerca del ser, el sentido, el lenguaje, la identidad, el deseo, la moral” (BRUÑA BRAGADO, 2016, p. 28).

El sueño invade a Ariadna que se duerme sobre una lápida. Las puertas del museo se abren para que los manifestantes realicen su labor destructora y el modelador los ayuda a colocar las bombas para minarlo. Despierta a Ariadna para salir a festejar, para abandonar el refugio. Pero ahora que han llegado, después de tan larga espera, la embarga un sueño profundo que no le permite moverse. El modelador la cubre con una sábana, como a sus estatuas, para protegerla del polvo y del tiempo. Se quedan inmóviles y en silencio hasta que, en el desenlace, se produce el estallido. La pareja del modelador y su modelo de mujer dormida o muerta, perecerá como "una fruta madura, como una formidable víscera descompuesta" (PERI ROSSI, 1969, p. 141). La descomposición posibilita nuevas composiciones. Destruir el archivo que está en el museo es minar las bases del relato histórico, de los modelos que crea el presente como memorable, abriendo nuevas posibilidades futuras.

El personaje de Ariadna representa la apertura femenina al llamado dionisíaco e instituyente de las luchas juveniles. La fuerza instintiva de este llamado se levanta contra un sistema violento, represivo, que aliena a las personas a través de lo espectacular y la publicidad, adormeciendo, intentando canalizar su insatisfacción. La convocatoria es una invitación a salir a las calles, a reunirse como comunidad en esos espacios públicos, a luchar. De esta manera emergen los conflictos violentos que se desarrollan en el escenario social. Contrastan con la instalación realizada por el modelador en el museo, titulada: "Los Estables", que representa lo instituido. Escultura de Museo, elaborada en solitario, aislada, creada fuera de la realidad política lo que revela el gesto negador de la agitación estructural de cambio que traen los jóvenes.

Ariadna debe elegir entre dos posibilidades: responder a la demanda del deseo del otro que la transforma en estatua, en objeto sublime, promesa, poesía realizada por el modelador para la posteridad; o aceptar la invitación de los jóvenes a sumarse a la fiesta revolucionaria, en donde circula el presente. De un lado está el refugio, del otro el riesgo; de un lado la promesa de la inmortalidad, del otro la vida y la muerte. Ella viene de un despertar, ha salido del mundo publicitario en donde era un cuerpo separado del rostro, una sombra de la otra, el 
cuerpo del riesgo fragmentado; un mundo en el que, alienada, se dejaba desmaterializar por la lógica del montaje fílmico.

El deseo de despertar, de fugarse de ese mundo opresivo, sintoniza con la necesidad de movimiento, de goce, del erotismo de los manifestantes. Según Citro, "las dimensiones corporales de las performances contribuyen a crear estados emotivos que son decisivos para la eficacia ritual, para la creación y renovación de la adhesión de los participantes a creencias, normas o valores allí recreados"(CITRO, 2000) Bien podría aplicarse a esta cita a la influencia emocional que ejercen los cuerpos de los manifestantes en Ariadna: "Como satélites y asteroides buscándote el pelo, la sonrisa, el dibujo de las manos, las líneas del cuello, las sábanas del cuerpo, los puertos de las ingles, la calle pulcra de las piernas emancipadas" (PERI ROSSI, 1969, p.123). Pero el temor la aleja de las calles nuevamente y la lleva al refugio del Museo.

En otros artículos se ha sido analizado el nombre de este personaje vinculándolo con el personaje del mito griego (VELJACIC, 2019, p.155). Analizaba el primer cuento de este tríptico, "Los juegos", asociando la idea del museo con el laberinto y, en el centro, el Minotauro simbólico del deseo inconsciente al que llegaba Ariadna. El minotauro, símbolo del creador encerrado por el tirano, en ese otro relato dialogado que es "Los reyes", de Julio Cortázar, funciona en su intertextualidad.

La imagen acústica del ruido de los manifestantes que se acercan, surge como un "mar mugiente", como "un toro en una lid", que llega con su furia instintiva, con su fuerza antigua y simple para destruirlo todo. Demolidas las paredes del laberinto-museo, de los refugios, el verdadero minotauro está ahora liberado en las calles. Y esta destrucción tiene, en su emergencia, algo de ritual festivo, triunfante, sexual, dionisíaco, inconsciente, mítico. Es una fuerza renovadora que se enfrenta a la violencia del sistema mortífero. La forma de revertir este orden está en el sacudimiento violento, vital, en el despertar, en el salir del aislamiento y la fragmentación para hacerse uno con esa fuerza continua y voraz que viene a destruir las cosas, las instituciones, los órdenes a los que se ven sometidos.

Ariadna se duerme y perece en el museo que estalla. Las fronteras que separan el adentro y el afuera se destruyen. Pero también se termina con la performance que la transforma en modelo, en un objeto de contemplación, en una estatua, en una conciencia adormecida y una subjetividad no nacida, incapaz de distanciarse de sí como para pensarse y elegir.

La apertura sensible y perceptiva generada por este acontecimiento extraordinario abre la posibilidad de experimentar nuevos cuerpos, de ponerlos en escena, de jugar con nuevos 
sentidos en un nuevo espacio, luchando por su legitimación. A través de su performance observamos los cambios socioculturales que permiten la emergencia de cuestionamientos sobre la construcción del género femenino.

Los jóvenes trazan una línea de fuga. Con sus acciones políticas divergentes del orden social se han transformado en "máquinas de guerra" que llegan para ponerle fin a un estado de la cultura, a una forma de vida, a una forma de arte, de vínculo, la sexualidad. Los jóvenes se tardan, pero cuando llegan, el sueño vence a Ariadna. Es un sueño acumulado, antiguo, que ha consumido sus fuerzas, pero también es el sueño gozoso de quien puede entregarse al sacrificio.

El gesto final del modelador es el de cubrirla. Ahora hay una entrega sacrificial al poder tanático revolucionario, a la animalidad de la furia de los sobrevividos. El sistema caracterizado por la explotación, la fragmentación de la identidad y la alienación a la que somete a los seres, la mercantilización, la fetichización del arte, la desigualdad, parece llegar a su fin en este estallido.

El refugio, en donde se conservan los Estables, ya no lo es. La fuerza negadora de los sobrevividos llega a minar este sistema desde su performance instituyente con su destrucción liberadora. Es el fin. La destrucción de los museos, de los refugios, nos dice que el futuro es ahora, en este espacio compartido que hace estallar aquello que lo aísla para recuperar su potencia viviente. Esta búsqueda de integración de lo abyecto o excluido -que será una temática de Peri Rossi-, pone fin a los relatos fundacionales, a los archivos, para dar lugar a las alteridades radicales.

Peri Rossi relata una escena del fin del mundo. Esta crisis en el orden simbólico se produce en momentos de un contexto de crisis históricas de la estructura social y de las instituciones vividas en los años 70 en Uruguay. Es posible observar su correlato de esta crisis histórica en el propio sujeto que se enfrenta al orden social dominante.

Los personajes del tríptico de Los museos abandonados tienen una cercanía con lo excluido, emergen o perecen entre los escombros excediendo y renovando el orden en cuestión (SUNIGA, 1968, p. 29). Estos relatos hacen estallar los modelos establecidos, habilitando nuevas representaciones éticas, estéticas y subjetivas.

En la predictadura uruguaya, la escritora capta los signos de los tiempos que se avecinan, anunciando la represión del terrorismo de Estado que la llevará a buscar refugio en Barcelona en un exilio del que ya no regresará. La actividad de la escritura de Peri Rossi, en su lucha contra la violencia política y contra el sujeto femenino modelado por esta sociedad, buscará recuperar la revuelta de una subjetividad capaz de enunciar su deseo entre las ruinas 
de una cultura, de una civilización.

\section{La zona de dolor de Lumpérica}

Diamela Eltit (1947) es una autora nacida en Santiago de Chile, que cuenta no solo con una extensa trayectoria literaria (abarcando desde la ensayística hasta la novela), sino también con una incursión en el arte de performance. En este artículo en particular nos importan dos cuestiones sobre la etapa inicial de producción artística: su vinculación con el CADA (Colectivo Acciones de Arte) y la escritura de su primera novela, Lumpérica (1983). A su vez, estos elementos mencionados interesan en relación al momento político chileno, ya marcado por la represión, la censura y el control de la dictadura ${ }^{3}$. Sobre esto, la autora comenta en Lazzara (2002, p.92):

(...) yo escribí con un censor al lado, en el sentido más simbólico del término, porque yo sabía exactamente que mi libro iba a dar a esa oficina. Entonces, tuve varias censuras: por una parte, este censor real que estaba allí aunque yo no lo conocía; por otra parte, las censuras que yo misma podía pensar -las mías-; y después, todas las censuras estéticas que uno trabaja para escribir un texto.

La elección de esta autora no es inocente. En un momento en el cual la resistencia y oposición era censurada a nivel de políticas estatales, Diamela Eltit se las ingenia para escribir una obra que trabaja con la materialidad del cuerpo femenino, con la materialidad de la obra narrativa y sus limitaciones, así como con la irrupción de lo "real" (su propio cuerpo atravesado por la performance) en ésta. La primera edición de Lumpérica (1983) se publica en Ediciones del Ornitorrinco, y en este artículo nos encargaremos de esta primera edición por dos motivos particulares: la configuración del libro y la disposición de las imágenes, así como también por la editorial en sí, caracterizada de esta forma por Gil (1982, p.4):

El ornitorrinco es un raro animalito que ha sobrevivido sobre nuestro planeta quién sabe por cuántos millones de años, escapándose a esa ley inexorable que enunciara Charles Darwin sobre la sobrevivencia del más fuerte. El ornitorrinco no lo es en modo alguno. Su secreto parece estar en que el hombre nunca se preocupó de él, jamás le molestó. Hasta ahora, que una empresa editora adopta su nombre para publicaciones heterodoxas.

El contexto editorial chileno está en este momento profundamente marcado por la represión y la censura como hemos mencionado. Si lo miramos como un caso aislado resulta curiosa la aparición de esta editorial, sin embargo, los años 1983-1986 se conocen como los

${ }^{3}$ En Chile, la dictadura comienza el 11 de septiembre de 1973 y culmina el 11 de marzo de 1990. 
años del "auge de la movilización social” (BASCUÑÁN, 2012, p.4). En este contexto, donde se popularizan las revistas de oposición, surge Ediciones del Ornitorrinco como una pequeña editorial independiente.

Sobre esto, Bascuñán (2012, p.9) plantea

\begin{abstract}
Ninguna revista en democracia, oficialista o no oficialista, ha tenido el tiraje que alcanzaron en su momento publicaciones como APSI, Análisis, La Bicicleta, Hoy o Cauce, que llegaron a vender hasta 100 mil ejemplares (Araya Jofré, p. 14). Boletines, trípticos y folletines informativos circularon por diversos centros de protección de los Derechos Humanos. En el ámbito de los libros, fueron editados por primera vez títulos por pequeñas editoriales que años después serían retomados por grandes empresas. Por ejemplo, Lumpérica (Diamelta Eltit, Las Ediciones del Ornitorrinco), por Casa de las Américas, el 2008; Silendra (Elizabeth Subercaseaux, Las Ediciones del Ornitorrinco), por Alfaguara, el 2000, Fidel Castro y la religión, conversaciones con Frei Betto (Carlos Alberto Libanio Christo, Pehuén) por Ocean Press, el 2006, y El viejo que leía novelas de amor (José Luis Sepúlveda, Emisión), por Tusquets, el 2009.
\end{abstract}

Por otra parte, sobre el Colectivo Acciones De Arte podemos decir que fue un colectivo artístico interdisciplinario que llevó a cabo durante la dictadura una serie de "acciones" o intervenciones en diferentes espacios, buscando evidenciar la situación de la sociedad chilena, así como del rol de arte en ese país, muchas veces mediante el controversial uso de los medios oficiales (avionetas del ejército, intervención en el Museo Nacional de Bellas Artes). Los integrantes de este grupo se conocieron en lo que Diamela denomina como "experiencia Artaud", de la mano de Ronald Kay.

Esta formación, además de ser una especie de antecedente del CADA, un espacio en donde miembros del colectivo coincidieron, funciona también como una posible formación a las intervenciones que la autora llevó a cabo por su cuenta. Sobre esto, ella dice en una entrevista con Neustadt, que "era un trabajo que nos permitía salir del soporte libro" (2001, p.92).

Es en este taller donde Eltit conoce a Lotty Rosenfeld, artista encargada de registrar dos performances vitales de Diamela directamente vinculadas con la novela que nos ocupa en este artículo. Zonas de dolor I y II son dos intervenciones que resultan centrales para entender no sólo a Lumpérica, sino que también al proyecto de escritura que propone Eltit.

Arriagada, citada en Urtubia Figueroa (2014, p 60), describe a las performances de esta forma:

"Zona de dolor I" consistió en una performance donde Eltit se auto-infringió varios cortes y quemaduras en los brazos y piernas, para luego leer algunos fragmentos de su aún no lanzada novela "Lumpérica" en un prostíbulo santiaguino, mientras su rostro se proyecta en las paredes exteriores de éste; luego, en "Zonas de dolor II", Eltit lava las veredas fuera del mismo prostíbulo. 
El cuerpo resulta central a Eltit. El cuerpo de mujer, el cuerpo flagelado, el cuerpo que es escondido pero que resulta funcional a un sistema neoliberal ${ }^{4}$. Es en y por el cuerpo que se escribe. Tanto para Urtubia Figueroa como para nosotras, no es para nada inocente que se haya vinculado a Lumpérica con estas acciones de arte "en la medida en que era justamente dicha acción la que le permitía poner en crisis los mecanismos represivos que actúan sobre el cuerpo y que marginan a 'ciertos' cuerpos" (pp. 60, 61).

Lumpérica es una novela en la cual la marginación se ubica en el centro de la plaza pública en la noche. L. Iluminada, el único personaje del cual conocemos su nombre, se encuentra con los pálidos y junto a ellos realiza una serie de rituales o acciones que tienen un alto tinte performático. A lo largo de la novela, comprendemos que L. Iluminada es el centro de la acción y los pálidos, ese conjunto de hombres, resultan accesorios a ella, si bien todos comparten un espacio. Están allí para mirarla, para complementarla.

Es una novela altamente fragmentada, que no sigue una linealidad temporal clara que se refleja no solo en la titulación de los capítulos (solo cuatro de los diez capítulos cuentan con nombre), sino también en su organización interna de los capítulos. Si bien comentaré fragmentos del capítulo 1 únicamente, consideramos que es importante mencionar el cambio de tipografía en los capítulos 2 y 7 - capítulos que coinciden con la narración de un interrogatorio en el cual se pregunta por la plaza pública, y la asistencia al accionar de L. Iluminada y los pálidos - y preguntarse qué es lo que aporta esto al libro.

Es importante también decir que L. Iluminada y los pálidos toman el centro del espacio público mediante el cuerpo:

L. Iluminada en el centro de la plaza empieza otra vez a convulsionar. Los pálidos rotan sus cabezas para tener un mejor ángulo y sólo entonces se dispersan sobre el césped (ELTIT, 1983, p.7).

Gimen por la luz, orgiásticos en sus convulsiones se masifican. Nadie diría que en Santiago de Chile podría ser esta bautizada para que esos se distiendan como gemas. Así es, con las ramas de los árboles que les lamen el rostro y ella se frota en su madera por el puro placer del espectáctulo. Sumida en el éxtasis de perder su costra personal para renacer lampiña acompañada por ellos que, como productos comerciales, se van a ofertar en esta desolada ciudadanía (ELTIT, 1983, p.8).

Siguiendo a Corbin (2013, p. 3) la escritura de Eltit realiza un movimiento hacia la reconsideración de la verdadera función de la materialidad biológica del cuerpo, colocando corporalidades con defectos en el centro como una forma de hablar, incluso cuando la voz

\footnotetext{
${ }^{4}$ Esta es la antesala de la década de mayor efecto del neoliberalismo en el Cono Sur, los años 90.
} 
misma pueda fallar. El cuerpo es de suma importancia en este texto, ya que toda la escritura pasa por él.

El cuerpo dice aquello que no se puede decir, aquello que se esconde detrás de aquél "tengo sed" que L. Iluminada repite a lo largo de la obra. Al mostrar estos cuerpos, al colocarlos en el centro de la acción en oposición a la marginalidad que los suele caracterizar, Eltit los resignifica, así como deja en evidencia su situación de resistencia en un momento crítico como lo es la dictadura. Para mostrar esto, tomando citas del capítulo 1.1, podemos ver a L. Iluminada y a los pálidos:

Se observa a sí misma (...) Se toca la piel en el mismo momento en que se curva más aún sobre el pasto, hasta que la cabeza cae sobre la tierra reblandecida. (...) Las piernas están abiertas en posición descuidada, y las balancea cada vez que en el centro de la plaza se recibe la luz.

(...)

Los pálidos han llegado ahora hasta ese mismo centro y empiezan su particular representación. Amontonan sus cuerpos y se dejan caer sobre el cemento. (...) Con sonidos guturales llenan el espacio en una alfabetización virgen que altera las normas de la experiencia (ELTIT, 1983, p.10).

Sigo aquí a Barrientos (2017, p. 146) para decir que

Los personajes de su obra tienen como denominador común su carácter performativo: no solo se insertan en la representación de un espectáculo o en el plano narrativo, sino también exhiben un discurso que se excede del lenguaje para llevarlo al plano corporal en escenarios de la periferia. De ese modo, los personajes, por medio de una performance, muestran orgullosamente las heridas autoinferidas en el proceso de subjetivación donde la búsqueda de algún punto de fuga desde el cuerpo y el texto hace que se tornen fragmentados y abyectos.

Gran parte de lo que acontece en esta obra, a su vez, sucede bajo la luz de un luminoso:

La piel de los pálidos muestra en sus aberturas su proceso y al fundirse en el siguiente demarcan infinitas posibilidades para cualquier mirada. Se arman y desarman en sus líneas, constituyendo un engañoso límite a la plaza.

Pero el luminoso los soporta. Sigue su tintineo con precisa regularidad. L. Iluminada en el centro. Suda a pesar del frío y por eso su carne se expone a la luminosidad. Más que nunca centellea allí controlando por sus contorsiones su claroscuro, mientras la luz toca los bancos de la plaza, los árboles y la disposición fabricada del césped (ELTIT, 1983, p.9).

Ese luminoso representa la venta del país al neoliberalismo. Ese luminoso que "está instalado sobre el edificio" y que es "una proposición de insanía para recubrir a los pálidos de Santiago que se han agrupado en torno a L. Iluminada nada más que como complemento visual para sus formas" (ELTIT, 1983, p. 8).

Para entender un poco más sobre el funcionamiento de la novela, su fragmentación y 
ver cómo se conjuga esta idea de la performance con la idea de lo efímero y el registro, podríamos detenernos un momento en la estructura de este primer capítulo. Si realizamos un esquema del mismo vemos que está dividido en cuatro partes, de las cuales solo tres tienen subtítulos. A su vez, ninguna de ellas tiene nombre. El esquema elemental sería así:

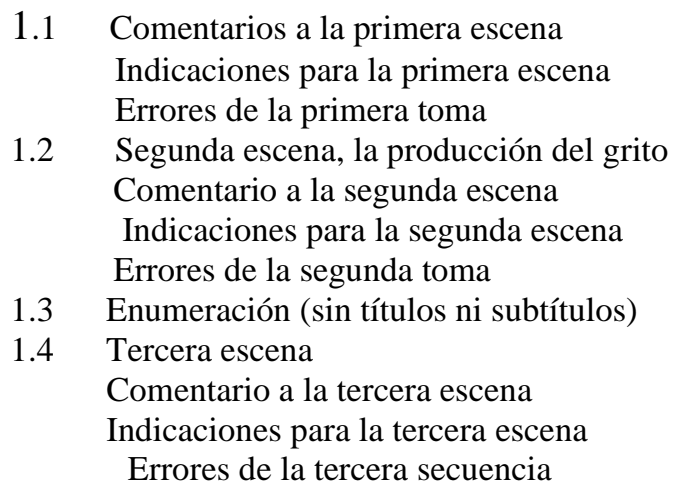

Al referirse a lo que acontece en la plaza con las palabras "escena", "toma" y "secuencia", se crea una idea de rodaje o filmación, de una intención de registrar aquello que acontece para la posterioridad. Esto no está estrictamente ligado con la idea de performance, pero teniendo en mente la idea de la salida del arte de los museos y hacia el espacio público, podemos considerar que aquí se ponen en diálogo conceptos que no refieren únicamente al lenguaje cinematográfico, que van más allá de éste y que, siguiendo la línea de lectura que se propone, forma parte del entramado vinculado con lo performativo y performático.

Los capítulos, al utilizar términos diferentes en la nomenclatura de los apartados, rompen con la linealidad. El fragmento 1.3 crea un desfasaje lógico entre la enumeración de las partes de los capítulos y su correspondencia con las "escenas". Las indicaciones, a su vez, si seguimos un orden lógico, deberían encontrarse escritas previo a la realización de la escena/toma/secuencia.

Las acciones nunca se llegan a concluir, se frustran. Los "actores" involucrados, los performers, saben que no se iba a terminar, que han fallado:

Ellos no la miraban, porque su quemadura no los conmovía y ella misma parecía que recogía los residuos de la plaza nada más que por llenar su tiempo, es decir, para agilizar su estadía. (...)

Aunque de verdad lo han repetido: gesto por gesto, paso por paso para el afuera de la cámara (...) Han rehecho la escena (...)

Porque sí el frío era real; cruzaba los huesos, sacaba el alma. (...)

Supieron desde siempre que la escena sería rehecha, nadie quiere para sí tales sufrimientos (ELTIT, 1983, p.34).

Tampoco sabemos si suceden en una misma noche, o en varias noches, no tenemos 
idea de temporalidad, de si las tomas se repiten o son parte de una única instancia de filmación. En cuanto a la irrupción de lo performativo-performático en esta narración, consideramos que esto está presente a lo largo de toda la novela, que no se puede restringir únicamente a las citas que serán incluidas a continuación, marcándolas como una primera aproximación al tema dentro del texto.

L. Iluminada tampoco permanece ausente del espectáculo. (...) Ella, plenamente teatral por la observación de sus movimientos camina hasta el centro de la plaza para detenerse bajo la luz del luminoso que la alumbra por intermitencias. Así se gesta su primera toma fílmica

Vean la experimentación en la plaza, no solitaria ni buscada: impuesta es/ trama su pose y permanece en ella por un lapso de vida. (ELTIT, 1983, pp.11, 17)

La gestación de esta toma fílmica parece nacer de algo vinculado más bien con lo teatral, aquello que requiere de un espectador inmediato, que es efímero y nunca igual en su producción, que con lo cinematográfico.

Consideramos que aquí es donde radica lo vital de la línea de lectura que se propone, que consiste en considerar a Lumpérica como un texto altamente performativo, registrado mediante la escritura y en relación estrecha con Zonas de dolor I y II mediante las fotografías que amplían esa idea de registro, referenciando directamente a la realidad, pero no de forma lineal, ya que la imagen de la tapa corresponde a Zonas de dolor II, y la de la página 141 corresponde a Zonas de dolor I. El registro, a su vez, no es perfecto, capaz de transmitir aquello que sucede de forma verdadera:

Señalar el vicio de la mirada, lo ficticio de su ángulo (ELTIT, 1983, p.13).

Ella misma no dejó ver su mejor ángulo, escurrió la mirada directa a la cámara, volvió el rostro ante el zoom (ELTIT, 1983, p.14).

El texto mismo, a su vez, nos da pistas sobre la separación de la filmación con una intención cinematográfica en el apartado 1.4, también vinculado con lo mencionado anteriormente sobre la posibilidad de captar verdaderamente lo que sucede:

5. ¿No será una alucinación en la plaza? ¿Esos cuerpos serán ramas? (...)

8. ¿Si todo esto fuera un error? ¿Y si ellos no fuesen más que un puñado de perdidos?

En cuanto a la cuestión de las imágenes que irrumpen en el texto, desde la tapa del libro (fig. 1) nos enfrentamos con la gran problemática que es la convivencia tensionada de varios lenguajes y registros — evidenciados en el primer capítulo- incluyendo los registros 
de las performances Zonas de Dolor I y II. Estas imágenes además tampoco siguen a la linealidad esperada: la imagen de tapa coincide con el registro de Zonas de dolor I, al igual que la imagen de la página 141 (fig. 2), sin embargo, sabemos que en esa intervención los cortes que están registrados en la página 141 son simultáneos a la proyección de su retrato en las paredes del prostíbulo.

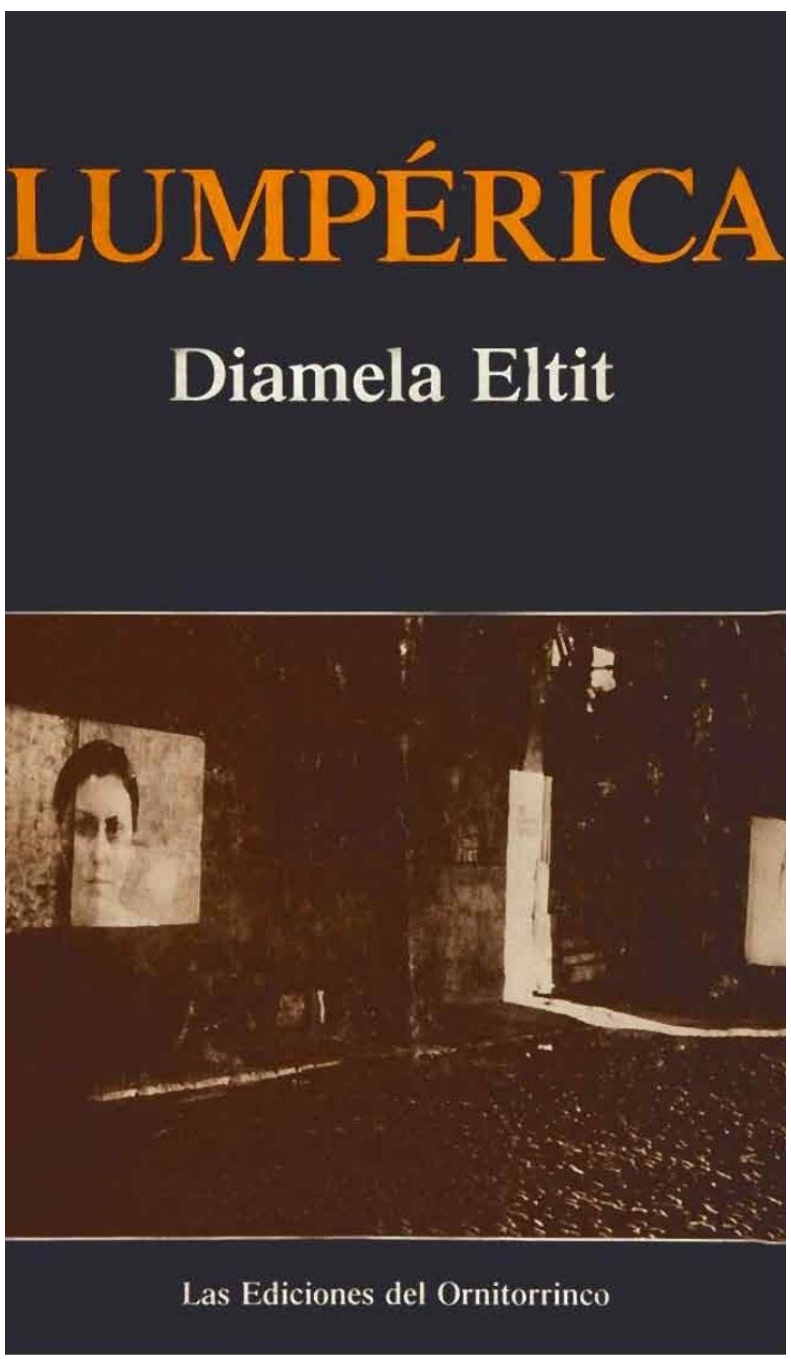

Figura 1: Tapa del libro Lumpérica, primera edición.

Fuente: Biblioteca Nacional de Chile. 


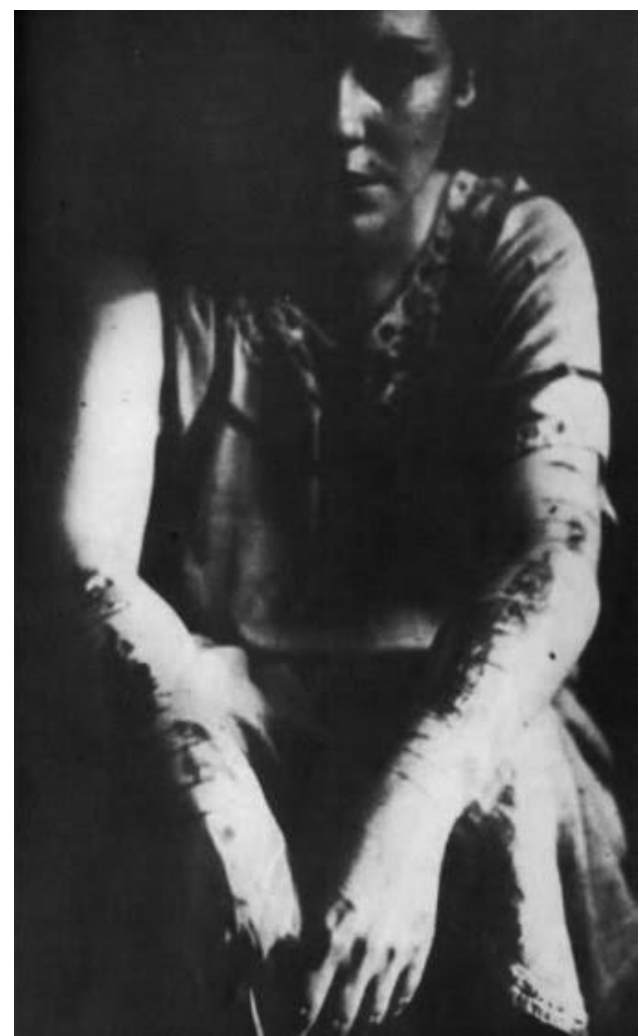

Figura 2: Imagen de la página 141.

Fuente: Biblioteca Nacional de Chile.

Las imágenes junto con la escritura, sin embargo, no se restringen mutuamente, no se encierran en sí mismas, sino que nos proponen un diálogo y una tensión que nos obliga a leer a esta novela no únicamente desde el lado de la creación ficcional, sino que nos incita a averiguar por qué estas imágenes están allí, qué le aporta la realidad a la novela. No es, a nuestro parecer, inocente, que en una novela sobre la marginación ocupando el lugar público, se encuentre presente de forma explícita una intervención de la autora en donde se produce un movimiento espacial del prostíbulo hacia lo público. Tampoco lo es que durante la realización de Zonas de dolor la autora haya leído fragmentos de la novela que nos ocupa en este artículo.

Según Olea (2008, p.186) "la fotografía nos lleva a proponer el fin del paradigma del libro como universo cerrado sobre su textualidad. El libro se abre a la imagen que excede la lectura y que lo conecta con otros espacios del lenguaje”. Para la autora, con la cual concordamos, la fotografía obliga a que se lea en el texto algo que no está, un sentido construido desde otro lugar.

En cuanto a la imagen que se encuentra en la tapa, Olea considera que aporta "la reflexión sobre la performance, la acción de arte que propone pensar el sentido de leer Lumpérica en un lugar marginal de la ciudad destinado a la prostitución, signo de la venta del país al neoliberalismo" (2008, p.186). Esta venta al neoliberalismo está claramente presente 
en el texto, en aquel luminoso que bautiza a L. Iluminada y a los pálidos:

Aunque no es nada novedoso, el luminoso anuncia que se venden cuerpos.

Sí, cuerpos se venden en la plaza.

A un precio no determinado. (...) Sus palabras caen en el vacío ampliando sus moléculas para petrificar lo eterno de la producción (ELTIT, 1983, p.10).

Los cortes y quemaduras en la imagen de la página 141, que en Zona de dolor I pueden ser comprendidos como una forma de protesta ante la condición social de la mujer que la lleva a la prostitución, al estar en la novela no pierden esa carga semántica, sino que se enriquece, se agranda. Nos permite interpretar ese dolor como un dolor de toda la sociedad chilena, de aquellos marginados no solo por la pobreza sino por la diferencia ideológica, que son también castigados por el sistema, reprimidos, forzados al ocultamiento. Los cortes representan el dolor de un país, de un continente en el cuerpo de la autora.

La autora, sin embargo, despliega todo esto en un texto que se potencia por la intervención de estas fotografías, que conllevan a reflexiones sobre la cuestión del retrato de autor, el retrato de una mujer y de la transformación, en una tradición artística patriarcal, de la mujer desde su existencia como objeto de arte hacia su representación como sujeto artístico.

\section{Conclusiones}

La revuelta de la contracultura en la segunda mitad de los años 60, particularmente en el emblemático 1968, provocó cambios profundos en las maneras de concebir las relaciones entre el arte, la política y la sexualidad. Se planteó una revolución que, en lo cultural, proponía disolver las fronteras entre el arte y la vida desde una neovanguardia que buscaba la revolución social. Se trató de una insurgencia generacional y global que interpeló al sistema capitalista cuestionando el entramado de sus fundamentos.

La represión que sufrió esta generación, volcada a la acción revolucionaria, en el Cono Sur, fue violenta, implacable y sistemática. Se presentaron formas de resistencia contra los regímenes autoritarios desde el periodismo, el canto popular, la literatura, el teatro, eludiendo la censura. Desde la contracultura se produjo un giro performático que transformó el cuerpo del artista-performer en el último reducto de una micro-revuelta que, desde su acción artística, intervenía políticamente en el desolado campo sociocultural.

En el período pre-dictatorial, en plena crisis de las instituciones, Peri Rossi critica al Museo como archivo de una cultura falologocéntrica, haciéndolo estallar, alegóricamente. En esta acción revolucionaria, perece el personaje de la mujer dormida, alienada en el mundo del espectáculo o en la fantasía del modelador, representante del imaginario femenino de la 
sociedad capitalista y patriarcal con la que se quería terminar.

Hemos observado cómo, en el trayecto que va desde la revuelta revolucionaria de estos años a las expresiones artísticas en las dictaduras del Cono Sur de los años 80, se produce un desborde de la literatura escrita a la performance como forma de resistencia.

Este giro se observa en el recorrido que va desde el cuento de Peri Rossi -en donde estalla el Museo refugio, el modelador y la mujer modelo-, a la performance "Zonas de dolor" de Diamela Eltit, en la que se produce el acontecimiento artístico con la presencia corporal de la artista en la plaza. El arte ya no puede encerrarse en los Museos, debe salir a la plaza pública a crear, desde la presencia corporal, el acontecimiento artístico.

La censura, la agresión y la violación de los derechos que ejerce la cultura dictatorial y patriarcal sobre los cuerpos de las mujeres se expresa, en la narrativa de la chilena, en la dicotomía entre una imagen de mujer funcional a la Patria, que se presenta de día en la plaza pública, y la mujer abyecta que emerge en la noche. Diamela Eltit se presenta con el cuerpo lacerado y doliente en su performance, como alegoría de la resistencia de una América Latina sometida a la violencia de los regímenes autoritarios.

\section{Referencias}

BARRÍA JARA, M. "Performance y políticas del acontecimiento. Una crítica a la noción de espectacularidad”. Aleteia. $\mathrm{N}^{\circ} 1$, Vol.21, 2011, p. 112.

BARRIENTOS, M. "La construcción estética de la imagen en la performance Zonas de dolor de Diamela Eltit”. Aisthesis, n. ${ }^{\circ}$ 61, julio de 2017, pp. 145-66. SciELO, doi:10.7764/aisth.61.8.

BASCUÑÁN, B. Editores y editoriales en Dictadura. Museo de la memoria y los derechos humanos, 2012.

BENJAMIN, W. Libro de los pasajes. Madrid: Edición Rolf Tiedemann, Akal, 2005.p. 462463

BRAVO, L. "La poética insurgente de Ibero Gutiérrez". [sic], Literatura y política, Revista de la Asociación de Profesores de Literatura del Uruguay. Año V-\#12, Agosto, 2015, p.94.

BRUÑA BRAGADO, M. Cartografía de una emoción inesperada: Cristina Peri Rossi gana el Premio Iberoamericano de Letras José Donoso 2019, en PÉREZ, C, SANGUINETTI, N. 56 años Viviendo con Cristina Peri Rossi. Montevideo: UDELAR-APLU, 2016, p. 28.

CITRO, S. "El cuerpo emotivo: de las performances rituales al teatro" En: Matoso, Elina 
(comp.) Imagen y representación del cuerpo, Serie Ficha de Cátedra, Teoría General del Movimiento. Publicaciones de la Facultad de Filosofía y Letras, Universidad de Buenos Aires. 2001, pág. 19-34.

CORBIN, M. “Archiveras anarquistas: Corporal Testimony in the Work of Diamela Eltit”.

Catedral Tomada: Journal of Latin American Literary Criticism, vol. 1, n. ${ }^{\mathrm{o}}$ 1, enero de 2013, pp. 1-17, doi:10.5195/ct/2013.29.

DA ROSA, J. Los narradores entre el realismo y sus fracturas en RAVIOLO-ROCCA, Historia de la Literatura Uruguaya Contemporánea, Montevideo: Ediciones de la Banda Oriental, 1996, p. 113-114.

DERRIDA, J. Mal de archivo: una impresión freudiana. Madrid: Trotta, 1997, p. 36.

ELTIT, D. Lumpérica. 1a ed., Santiago de Chile: Las ediciones del Ornitorrinco, 1983.

FISCHER-LICHTE, E. Estética de lo performativo. Madrid: Abda Editores: 2011.

GALLEGOS, A. El riesgo y la cuestión política. https://rephip.unr.edu.ar/bitstream/handle/2133/713/El\%20riesgo\%20y\%20la\%20cue sti\%C3\%B3n\%20pol\%C3\%ADtica_A1a.pdf?sequence=1\&isAllowed=y

GARBATZKY, I. Los ochenta recienvivos. Poesía y performance en el Río de la Plata. Rosario. Beatriz Viterbo, 2013, p.25.

GARRAMUÑO, F. La experiencia opaca. Buenos Aires: FCE, 2009, p. 34-35.

GIL, A. "Ediciones del ornitorrinco". Bravo, n 55, Febrero 1982, p. 94.

GOFFMAN, E. La presentación de la persona en la vida cotidiana. Madrid: Amorrortu, 1993.

KRISTEVA, J. Sentido y sin sentido de la revuelta. Literatura y psicoanálisis. Buenos Aires: EUDEBA, 1998, p. 94-95.

LAZZARA, M. J. Diamela Eltit: conversaciones en Princeton. Princeton: Program in Latin America Studies, Princeton University, 2002.

MIRZA, R. La escena bajo vigilancia. Teatro, dictadura y resistencia. Montevideo: Ediciones de la Banda Oriental, 2007, p. 73.

NEUSTADT, R. CADA día: la creación de un arte social. Santiago de Chile: Cuarto Propio, 2001.

OLEA, R. Contrapuntos narrativos: lenguaje verbal e imagen visual en Lumpérica de Diamela Eltit. 2008. repositorio.uc.cl, https://repositorio.uc.cl/handle/11534/11632 PERI ROSSI, C. “El tiempo de los jóvenes: Cristina Peri Rossi”. Marcha, 27 de diciembre 1968. 
Los museos abandonados. Montevideo: Arca, 1969, p. 120-141.

RAMA, A. La generación crítica 1939- 1969. Montevideo: Arca, 1972, p.1.

SUNIGA, A Cristina Peri Rossi en "El tiempo de los jóvenes: Cristina Peri Rossi”, Marcha, 27 de diciembre 1968, p 29.

TAYLOR, D. "Hacia una definición de Performance” ponencia en New York: NYU. 2001.

TURNER, V. Antropología ritual. México: Instituto Nacional de Antropología e Historia. 2002.

URTUBIA FIGUEROA, C. La emergencia del arte de género en Chile: apuntes sobre la relación entre el activismo de género y las artes visuales durante la Dictadura Militar. Universidad de Chile, 2014.

VELJACIC, K. Representaciones de lo femenino en "Los juegos" de Los museos abandonados en PÉREZ, C, SANGUINETTI, N. 56 años Viviendo con Cristina Peri Rossi. Montevideo: UDELAR-APLU, 2016, 155-163. 